\title{
Adenocarcinoma in Adenomatous Polyposis Coli
}

National Cancer Institute

\section{Source}

National Cancer Institute. Adenocarcinoma in Adenomatous Polyposis Coli. NCI

Thesaurus. Code C4134.

Adenocarcinomas developing in colorectal adenomas in patients with a history of adenomatous polyposis coli. The mean age of development of adenocarcinoma is about 40 years. 